\title{
Hybridization between GM soybean (Glycine max (L.) Merr.) and wild soybean (Glycine soja Sieb. et Zucc.) under field conditions in Japan
}

\author{
Aki MIzUGUTI ${ }^{1 *}$, Kentaro OHIGASHI ${ }^{1}$, Yasuyuki YoshimURA ${ }^{1}$, Akito KAGA ${ }^{2}$, Yosuke KUROdA ${ }^{2,3}$ and Kazuhito MATSUO ${ }^{1}$ \\ 1 National Institute for Agro-Environmental Sciences, Tsukuba, Ibaraki, Japan \\ 2 National Institute of Agrobiological Sciences, Tsukuba, Ibaraki, Japan \\ 3 Present address: National Agricultural Research Center for Hokkaido Region, National Agriculture and Food Research Organization, \\ Memuro, Hokkaido, Japan
}

\begin{abstract}
Accumulation of information about natural hybridization between GM soybean (Glycine max) and wild soybean (Glycine soja) is required for risk assessment evaluation and to establish biosafety regulations in Japan. This is particularly important in areas where wild relatives of cultivated soybean are grown (i.e. East Asia including Japan). To collect information on temporal and spatial factors affecting variation in hybridization between wild and GM soybean, a two year hybridization experiment was established that included one wild soybean and five GM soybean cultivars with different maturity dates. Hybridization frequencies ranged from 0 to $0.097 \%$. The maximum hybridization frequency $(0.097 \%)$ was obtained from wild soybean crossed with GM soybean $\mathrm{cv}$. AG6702RR, which were adjacently cultivated with wild soybean, with 25 hybrids out of 25741 seedlings tested. Cultivar AG6702RR had the most synchronous flowering period with wild soybean. Ten hybrids out of 25741 were produced by crossing with cv. AG5905RR, which had the second most synchronous flowering period with wild soybean. Most hybrids were found where GM and wild soybeans were adjacently cultivated, whereas only one hybrid was detected from wild soybean plants at $2 \mathrm{~m}, 4 \mathrm{~m}$ and $6 \mathrm{~m}$ from a pollen source (GM soybean). Differences in flowering phenology, isolation distance and presence of buffer plants accounted for half of the variation in hybridization frequency in this study. Temporal and spatial isolation will be effective strategies to minimize hybridization between GM and wild soybean.
\end{abstract}

Keywords: buffer plant / distance / flowering overlap / flowering synchronism

\section{INTRODUCTION}

With increasing global commercial cultivation of genetically modified (GM) crops, an accumulation of information on natural hybridization between crops and their wild relatives is required for development of regulation for use of GM crops in Japan, because there are concerns that hybridization between GM crops and their wild relatives may cause negative impacts on the ecosystem. Ellstrand (2003) suggested that gene flow from GM crops into wild relative populations may have the same impacts as traditional crop genes. By contrast, Hancock (2003) suggested that some transgenes (e.g. cold, drought, and heavy metal tolerance; improved nutrient uptake; altered development) may cause dramatic adaptive shifts in hybrids and

*Corresponding author: mizuguti9@gmail.com subsequent generations and result in negative impacts on ecosystems. Even if hybridization frequency is low, introgression of transgenes through hybridization can lead to changes in the growth rate of wild relative populations if the fitness of hybrids and/or their subsequent generations are increased by the transgene (Haygood et al., 2003; Hooftman et al., 2008; Thompson et al., 2003; Wolf et al., 2001). Estimating hybridization frequencies between GM crops and their wild relatives is a first step towards evaluation of the introgression of a transgene. For these reasons, understanding the factors that affect hybridization between GM crops and their wild relatives are important and useful for the development of regulation in countries where wild relatives of GM crops are distributed. Empirical studies have clarified the effects of factors related to isolation distance and wind direction from GM crops 
to wild relatives on hybridization between GM crops and wild relatives (D'Andrea et al., 2008; Song et al., 2003).

GM soybean production represents $76.9 \%$ of the global soybean crop and the GM cultivation area is increasing year by year (ISAAA, 2009). No GM soybean, however, is currently being cultivated commercially in East Asia. In East Asia, wild soybean (Glycine soja Sieb. et Zucc.), the closest wild relative of cultivated soybean (Glycine max (L.) Merr.), is a domestic species (Oka, 1983; Tateishi and Ohashi, 2001; Xu et al., 2002). When GM soybean cultivation begins in East Asia, hybridization with wild soybeans is expected because there is no postzygotic isolation between wild and cultivated soybean (Karasawa, 1936; Kwon et al., 1972). In addition, wild soybean is a common weed and grows in semi-natural habitats including grasslands and roadsides (Tateishi and Ohashi, 2001), often around the cultivated soybean fields. Natural hybridization frequencies between cultivated and wild soybean have been noted to be very low because of their autogamous sexual reproduction (Carlson and Lersten, 2004). However, hybrid derivatives between cultivated and wild soybean can survive without any intervention for at least three years in semi-natural conditions (Oka, 1983). Therefore, we should understand the factors that affect natural hybridization between GM and wild soybean to minimize the introgression of transgene through hybridization by use of effective tools.

In Japan, two experiments were managed under conditions where the flowering periods of cultivated and wild soybean were controlled and they were adjacently planted to create a worse case scenario for hybridization between cultivated and wild soybean. Nakayama and Yamaguchi (2002) detected five hybrids between a conventional cultivated soybean (cv. Tanbaguro) and wild soybean out of 686 progeny plants. Cultivar Tanbaguro and wild soybean were adjacently planted and their flowering periods were overlapped for about 30 days. Mizuguti et al. (2009) detected one hybrid between glyphosate-tolerant GM soybean (cv. AG3701RR) and wild soybean out of 32502 progeny plants tested. Cultivar AG3701RR and wild soybean were adjacently planted and their flowering periods overlapped 18-24 days. The variation in hybridization frequencies between the above two experiments were probably caused by the differing levels of flowering synchrony, although other factors may also have influenced the results. In addition, natural hybridization frequency between GM and non GM soybean is known to be controlled by spatial factors (Abud et al., 2007; Yoshimura et al., 2006). Therefore, temporal and spatial factors may be effective tools to reduce hybridization frequency between GM and wild soybeans.

Hence, the following experiments were designed to understand factors affecting the hybridization frequency between GM and wild soybean. The flowering periods of GM soybeans were managed by selecting specific cultivars and sowing dates. The spatial arrangements were managed by using isolation distances and buffer plants so that the effectiveness of temporal and spatial isolation in minimizing hybridization between GM and wild soybean could be assessed.

\section{RESULTS}

\section{Hybridization frequency}

Thirty-eight of 204881 seedlings survived after spraying with glyphosate. All surviving seedlings were confirmed to have the glyphosate-tolerant protein by the immunochemical chromatographic test. Twenty SSR markers were screened to find polymorphisms between wild and GM soybean. Among those markers, the combination of three SSR markers (Satt076, Satt277 and Satt423) had the ability to distinguish not only GM soybean from wild soybean but also all five GM soybean cultivars efficiently. Based on the three markers, genotypes of the 38 herbicide tolerant plants were found to be heterozygous at all three loci. Those heterozygous genotypes were composed of a wild soybean allele and GM soybean alleles. Among 38 plants analyzed, 10 plants had GM soybean alleles from cv. AG5905RR, and 28 plants had GM soybean alleles from AG6701RR. Thus, all 38 herbicide tolerant plants were hybrids that originated from pollination of wild soybean by GM soybean in 2007 .

No hybrids were detected in 2006. In 2007, we used the later GM soybean cultivars and delayed the sowing dates of GM soybean than the experimental condition in 2006 to increase overlap of flowering periods between wild and GM soybeans. As a result, a total of 38 hybrids between GM and wild soybean were detected from 20 net walls of climbing wild soybean in 2007 (indicated with an asterisk in Fig. 1). Several hybrids were found on 17 net walls, ranging from 1 to 6 hybrids per wall, in the mixed planting area, whereas there were few hybrids per wall in the spatial planting area in 2007.

In the mixed planting area, hybridization frequency between cv. AG5905RR and wild soybean was $0.039 \%$ (10 hybrids of 25741 seedlings) and between cv. AG6702RR and wild soybean was $0.097 \%$ (25 hybrids of 25741 seedlings) in 2007 (Tab. 1). In the spatial planting area, 3 hybrids with cv. AG6702RR were detected at 2, 4 and $6 \mathrm{~m}$. No hybrids with cv. AG5905RR were detected at any distance.

The hybridization frequencies were compared by using two-sided $95 \%$ confidence intervals of each experimental approach (Tab. 1; Fig. 2). In 2007, the confidence intervals of hybridization frequency between cv. AG5905RR and wild soybean overlapped only slightly 


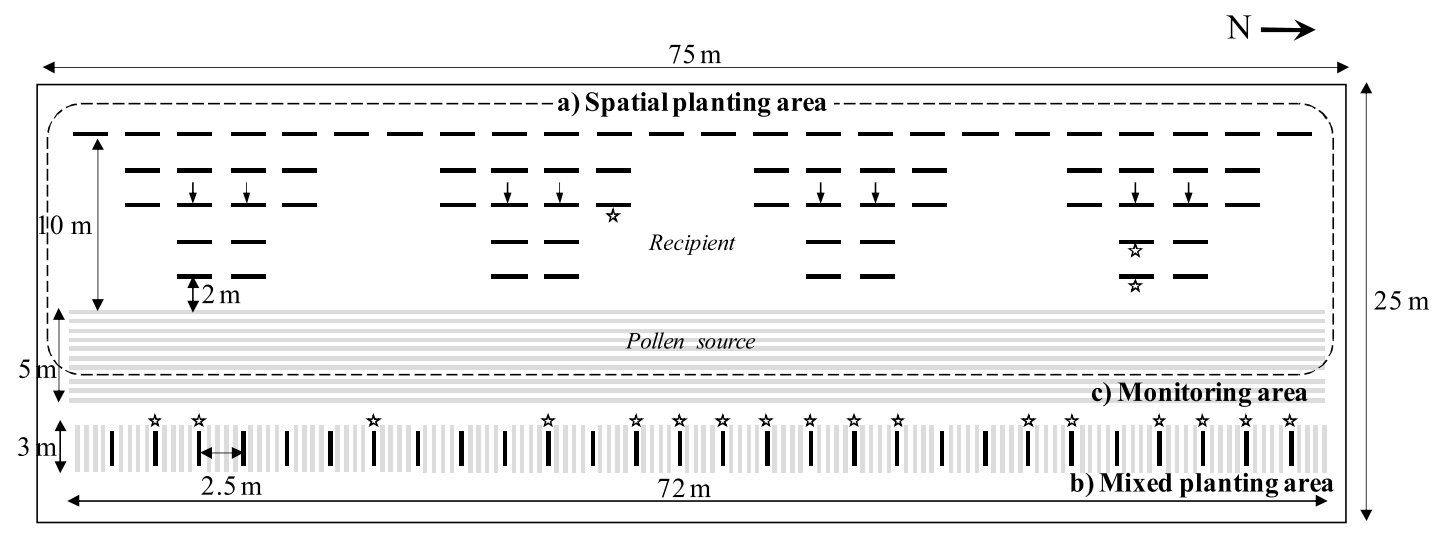

a) Spatial planting area (a part of pollen source)

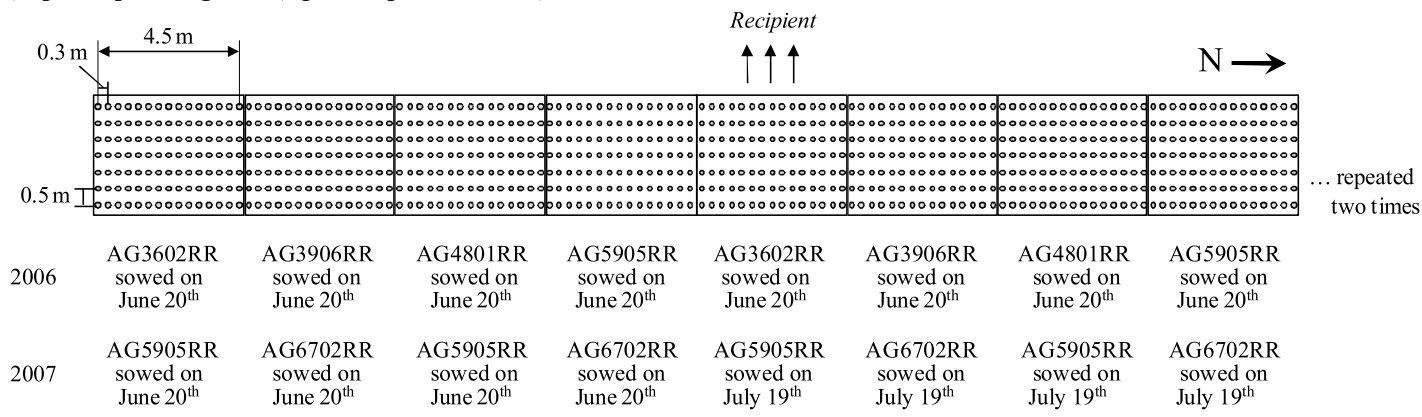

b) Mixed planting area (a part of area)

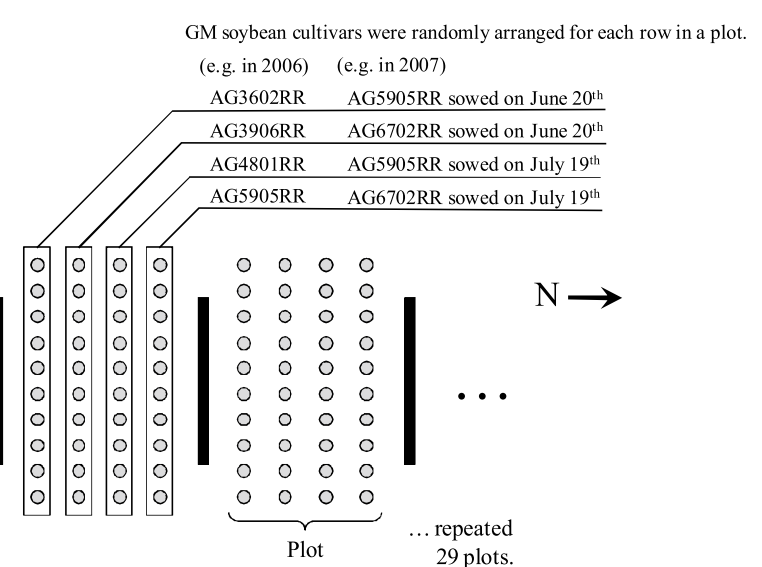

Figure 1. Experimental field design for the analysis of factors affecting hybridization between GM and wild soybeans.

Short heavy lines indicate net walls on which wild soybeans plants were planted and climbed. The gray heavy lines indicate GM soybean planting. The down-arrows indicate the walls on which the numbers of flowers of wild soybean were counted in the spatial planting area (8 walls). The asterisks indicate the walls on which the hybrids between GM and wild soybeans were detected in 2007 (20 walls).

a) Spatial planting area consisted of a GM soybean zone (pollen source) and 72 walls on which wild soybean were planted (recipient). b) Mixed planting area consisted of 29 blocks in which GM soybean were planted and 28 walls on which wild soybean were planted. c) Monitoring area consisted of three rows on which GM soybean were planted to monitor flowering phenology.

The detail drawing indicates arrangements of GM soybean cultivars in pollen source. The individual spots indicate hill-positions of GM soybean plants. Sowing GM soybean cultivar was different in each box. 
A. Mizuguti et al.

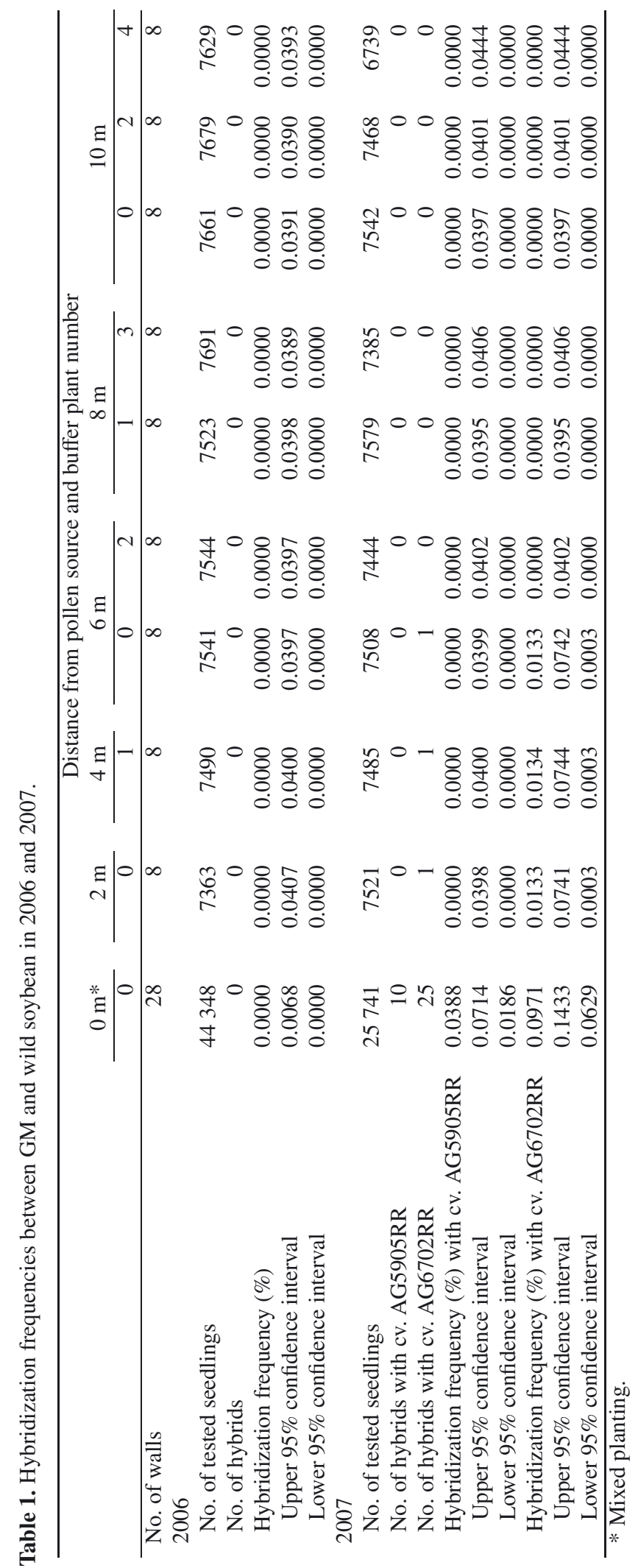


(a)

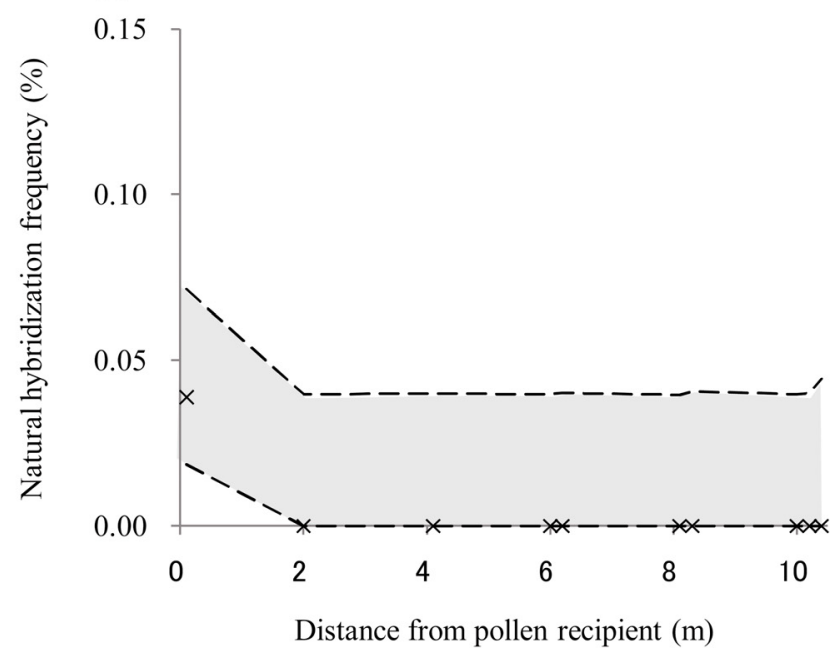

(b)

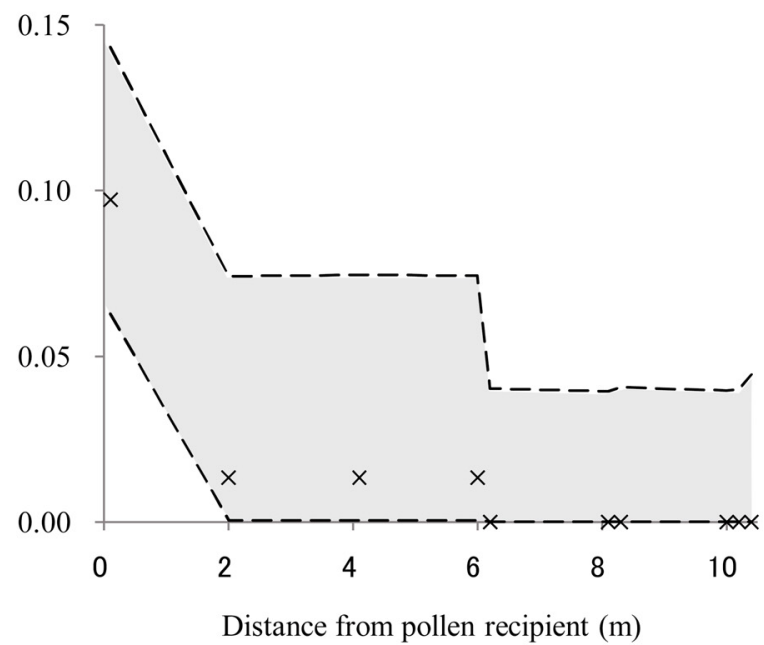

Figure 2. Effects of temporal and spatial isolation on hybridization frequency between GM and wild soybeans in 2007. Hybridization frequencies with GM soybean cultivars; (a) AG5905RR, (b) AG6702RR are shown. $\times$ marks indicate hybridization frequencies for each distance and each barrier number. The gray zones show upper and lower $95 \%$ confidence intervals.

with that between cv. AG6702RR and wild soybean in the mixed planting area (distance of $0 \mathrm{~m}$ ). The confidence intervals of hybridization frequency between cv. AG6702RR and wild soybean in the mixed planting area overlapped only slightly with that in the distance of $2 \mathrm{~m}$, $4 \mathrm{~m}$ and $6 \mathrm{~m}$ with no buffer plants, and didn't overlap with that in the distance of $6 \mathrm{~m}$ with 2 buffer plants, $8 \mathrm{~m}$ and $10 \mathrm{~m}$. Conversely, the confidence intervals of hybridization frequency between $\mathrm{cv}$. AG5905RR and wild soybean in the mixed planting area overlapped mostly with that of hybridization frequencies in the spatial planting area. However, the statistical power to differentiate was weak because of insufficient sample size in the spatial planting area.

\section{Flowering synchrony}

Flowering phenology of wild soybean was similar between experimental years (Fig. 3). Wild soybean flowered later than GM soybean cultivars in both years. The total number of observed flowers of wild soybean was about 3000 per net wall and substantially greater than that of GM soybean. The flower numbers of GM soybean averaged 80-280 per hill, and the later cultivars (i.e. cvs. AG5905RR and AG6702RR) had higher numbers than the other earlier cultivar.

In 2006, flowering phenology of three GM soybean cultivars, cvs. AG3602RR, AG3906RR and AG4801RR were similar to each other and there was a 10-day overlap in flowering period with wild soybean (Fig. 3a). The flowering peaks for these three GM soybean cultivars were separated into two peaks within an individual plant, but neither of the flowering peaks overlapped with a flowering peak of wild soybean which was 34 days later. The flowering phenology of the cultivar, cv. AG5905RR, was different from the above three cultivars and it had a higher number of flowering overlap days (15 days) and more synchronous flowering peaks ( 24 days).

The flowering overlap days and peak were longer and closer to that of wild soybean in 2007 than in 2006 because later-flowering GM soybean cultivars were used: cvs. AG5905RR and AG6702RR (Fig. 3). The number of flowering overlap days between the two GM soybean cultivar and wild soybean were similar regardless of sowing date; 24 and 25 days for standard and late sowing cv. AG6702RR, respectively, and 12 and 15 days for cv. AG5905RR (Fig. 3b). However, flowering peak of GM soybean cultivars that were sown in July was closer to wild soybean (10 days for $\mathrm{cv}$. AG5905RR and 7 days for cv. AG6702RR) than for plants sown in June (25 days for cv. AG5905RR and 20 days for cv. AG6702RR) (Fig. 3b).

\section{Effect of temporal and spatial factors}

"GM soybean cultivar" was defined as a parameter to test for the effect of temporal factor. For these reasons, the pollen parent of hybrids could be detected in regard to GM soybean cultivar, but not sowing date. "Distance" and "buffer plant" were defined as parameters for the effects of spatial factors. These parameters were used 
A. Mizuguti et al.
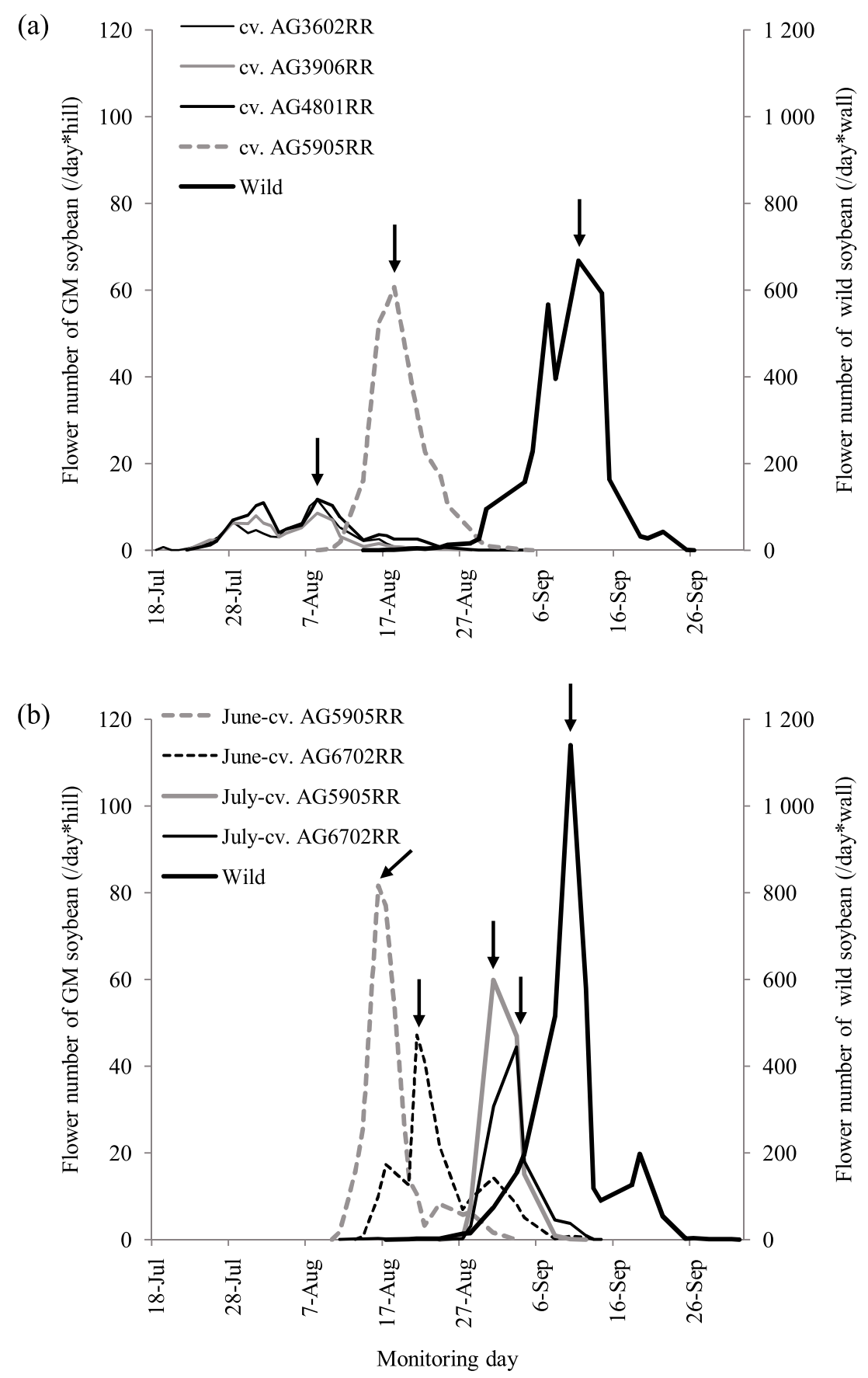

Figure 3. Flowering phenologies of GM and wild soybeans in (a) 2006 and (b) 2007.

Flower numbers represent the average for each monitoring day. The arrows indicate the peak flowering days. 
Hybridization between GM and wild soybeans

Table 2. Effects of factors on hybridization frequency between GM and wild soybean in 2007.

\begin{tabular}{lcccccc}
\hline Factors & Coefficient & SE & $t$ value & $P(>|t|)$ & LR Chisq* & $P(>$ Chisq) \\
\hline $\begin{array}{l}\text { Temporal factor } \\
\text { GM soybean cultivar (cv. AG6702RR) }\end{array}$ & 1.03 & 0.32 & 3.19 & 0.002 & 11.56 & 0.001 \\
$\quad \begin{array}{l}\text { Spatial factors } \\
\text { Distance }\end{array}$ & -0.59 & 0.17 & -3.37 & $<0.001$ & 40.43 & $<0.001$ \\
$\quad$ Buffer plant & -0.44 & 0.95 & -0.47 & 0.640 & 0.24 & 0.627 \\
\hline *Likelihood ratio Chi-square statistics. & & & & & &
\end{tabular}

for the generalized linear model to explain the variation in hybridization frequency. The coefficients of "GM soybean cultivar" and "distance" in the model were significantly different from zero (Tab. 2), and hybridization with cv. AG6702RR was higher than with cv. AG5905RR; distance was found to be negatively correlated with hybridization frequency. In addition, the significant effects of "GM soybean cultivar" and "distance" were detected by the analysis of deviance for the model fits. The deviance explained by this model was $48.5 \%$. Thus, half of the variation in the hybridization frequency was explained by "GM soybean cultivar", "distance" and "buffer plant".

\section{DISCUSSION}

\section{Hybridization frequency}

Hybridization frequencies ranged from 0 to $0.097 \%$ in our experiments (Tab. 1). The two-sided 95\% confidence intervals of our maximum value $(0.097 \%$ : hybrids with cv. AG6702RR in the mixed planting area in 2007) were $0.063-0.143 \%$ under the condition within the approximately 25 day overlap in flowering periods. Results of Nakayama and Yamaguchi (2002) estimated a hybridization frequency of $0.23-1.69 \%$ (5 hybrids detected in 686 samples, i.e. $0.73 \%$ ) under the condition of $50 \mathrm{~cm}$ interval plantings in a checkerboard pattern within the approximately 30 day overlap in flowering periods. Therefore, our maximum values were lower than that of Nakayama and Yamaguchi (2002). In contrast, Mizuguti et al. (2009) estimated hybridization frequency at $0.0001-0.017 \%$ ( 1 hybrid detected in 32502 samples, i.e. $0.003 \%$ ); this value was lower than our maximum value. These results suggest that hybridization frequency between wild and cultivated soybeans varies even if their flowering periods were synchronized and the plants were adjacently cultivated.

In our experiment, the hybrids were detected on 17 out of 28 walls in 2007 and none out of 28 walls in 2006 in the mixed planting area. The walls detecting hybrids were randomly placed (Fig. 1). Nakayama and Yamaguchi (2002) found that hybridization randomly occurred in four out of 23 wild soybean plants arranged with a soybean cultivar in a checkerboard pattern, whereas Mizuguti et al. (2009) found only one hybrid from 51 wild soybean plants on six ridges. It has been reported that insects visiting cultivated and wild soybean flower, such as leaf-cutter bee (Megachile turugensis Cockerell), halictid bee (Halictus sp.), and honey bee (Apis cerana Fabricius), may be pollen vectors between wild and cultivated soybeans (Mizuguti et al., 2008a; Nakayama and Yamaguchi, 2002). In the present study, the random occurrence of hybridization is likely associated with the mobility pattern of insects present in the field.

\section{Effects of temporal and spatial factors}

Hybridization frequencies (Tab. 1) varied among the different experimental approaches (mixed planting, isolation distance, number of barriers, GM soybean cultivars and experimental year). In 2006, the flowering phenologies were not synchronized and no hybrid was detected, whereas the flowering phenologies were synchronized and 38 hybrids were detected in 2007 (Fig. 3; Tab. 1). The hybridization frequency of wild soybean with cv. AG5905RR, which had a shorter flowering overlap period and asynchronous flowering peak, was lower than hybridization of wild soybean with cv. AG6702RR in 2007 (Tab. 1; Figs. 2 and 3). The statistical analysis on the experiment in 2007, using a generalized liner model, indicated that the significant effect of "GM soybean cultivar" was detected (Tab. 2). The effect of "GM soybean cultivar" was most likely due to difference in flowering phenology.

These results indicate that the temporal isolation, specifically the difference in flowering phenologies of GM soybean cultivars, largely influenced the frequency of hybridization between wild and GM soybean. The hybridization between GM and wild soybean could be minimized by using soybean cultivars with earlier maturity dates and earlier sowing dates. Sameshima (2000) surveyed the initiation date of flowering in major soybean cultivars under controlled environments in accumulated temperature and day length and found that the initial date of flowering could be estimated using accumulated temperature and day length in Japan. Ohigashi et al. (2009) 
suggested that initiation, peak and end of flowering in cultivated soybean (cv. Enrei) could be estimated by the improved model of Sameshima (2000). Mizuguti et al. (2008b) cultivated several regional populations of wild soybean in the same experimental field and surveyed the flowering phenology. They showed a regional cline of flowering phenology according to the latitude of the original regions and suggested that flowering phenology of wild soybean could be also estimated using accumulated temperature and day length. Therefore, if the flowering phenologies of wild soybean population in a region can be determined, one can then estimate how the flowering period of GM soybean could be adjusted to minimize hybridization frequency between GM and wild soybean. From this perspective, our results provided useful information for establishing strategies to minimize hybridization frequency between GM and wild soybean through the use of temporal isolation.

The spatial isolation between GM and wild soybean reduced hybridization lower than one-tenth (three hybrids were detected in the spatial planting area relative to 35 hybrids in mixed planting area of 2007; Tab. 1). The reduction was considerable, because overlaps of the confidence intervals in hybridization frequencies were zero or very small between the mixed planting area and the spatial planting area, despite the insufficient numbers of samples (Tab. 2; Fig. 2b). Additionally, the significant effect of the spatial parameter "distance" was detected (Tab. 2). These results suggest that hybridization could be restricted using isolation distance, as is common with other crops such as oilseed rape, rice, and maize (Della Porta et al., 2008; Hüsken and Dietz-Pfeilstetter, 2007; Rong et al., 2007). According to these result, it is prudent to cut down weed communities around edge of farmland in which wild soybean may grow, during the flowering period of GM soybean, to maintain isolation distances.

A combination of isolation distance and temporal isolation would provide even a more effective prevention of hybridization. Similar reductions in hybridization rates have been reported for corn, a wind pollinating species (Della Porta et al., 2008; Halsey et al., 2005; Messeguer et al., 2006; Palaudelmas et al., 2008; Rognli et al., 2000). These studies also evaluated the relationship between flowering overlap, distance, and hybridization frequency, and showed that increasing temporal isolation reduced the spatial distance required to achieve lower levels of cross pollination.

In our study, buffer plants did not have a clear effect on hybridization (Tab. 2). Although we expected that the presence of other wild soybean walls would assist in minimizing hybridization, we were not able to detect an effect. The effectiveness of buffer plants to reduce hybridization between GM and non-GM crops has been documented for other insect-pollinated crops, such as oilseed rape (Morris et al., 1994; Staniland et al., 2000) and safflower (McPherson et al., 2009). Buffer plants are also likely effective in reducing hybridization between GM soybean and their wild relatives, but further studies will be required quantify this effect.

In our model, a total of $48.5 \%$ of the variation in hybridization frequency was explained by three parameters (GM soybean cultivars, distance and buffer plant). The deviance unexplained by our model was $51.5 \%$; these may be explained by insect behavior, the subtle difference of the flowering periods and the number of flowers among wild soybean plants and the interactions among the three main parameters that could not be estimated by the model. Although some type of interaction among these three parameters could have occurred, with such a low number of hybrids for cv. AG5905RR, there was no way to properly estimate interaction effects.

\section{MATERIALS AND METHODS}

\section{Plant materials}

Glyphosate-tolerant GM soybean (Roundup Ready soybean 40-3-2, Monsanto Canada Inc.) cv. AG3602RR (Maturity Group III in the US cultivar classification), cv. AG3906RR (Maturity Group III), cv. AG4801RR (Maturity Group IV), cv. AG5905RR (Maturity Group V) and cv. AG6702RR (Maturity Group VI) were used in these experiments. Flowering period varied among cultivars and number of days to flowering increased with a later Maturity Group. Seeds of wild soybean were collected from a natural population growing at the National Institute for Agro-Environmental Sciences (NIAES), Tsukuba Ibaraki Prefecture, Japan. To break seed dormancy, the seed coats of wild soybean were scarified with sandpaper prior to sowing.

\section{Sowing date}

Wild soybeans were sowed on May 22th in 2006 and 2007. To promote flowering synchronization between wild and GM soybeans, the GM soybean cultivars used and the sowing date of GM soybean were changed between years. GM soybean cvs. AG3602RR, AG3906RR, AG4801RR and AG5905RR were sowed on June 20th 2006, approximate one month later than the wild soybean. Cultivars AG5905RR and AG6702RR were sowed on June 20th and July 19th 2007, approximately one month and two months after the wild soybean were sowed. 


\section{Planting density}

GM soybeans were planted at a density of approximately 9 hills. $\mathrm{m}^{-2}$ (distance between rows $=0.5 \mathrm{~m}$; two plants per hill after thinning). Wild soybeans were grown along the net wall ( $2 \mathrm{~m}$ wide $\times 1 \mathrm{~m}$ high) placed perpendicular to the ground, because wild soybean is a climbing plant. Three plants of wild soybean were grown per wall, with $1 \mathrm{~m}$ intervals between plants.

\section{Field design}

The natural hybridization experiment and monitoring of flowering of GM and wild soybean was conducted in the experimental field of NIAES $(75 \times 25 \mathrm{~m})$ in both 2006 and 2007 (Fig. 1). The experimental field was divided into three areas. The first area was designed to estimate the effect of buffer plant walls and distances between GM and wild soybean (spatial planting area; Fig. 1a); in the second area, GM and wild soybean plants were planted alternately and adjacent to each other (mixed planting area; Fig. 1b); the third area was planted only with GM soybean cultivars to monitor the flowering phenologies (monitoring area; Fig. 1c).

The spatial planting area consisted of a GM soybean zone (pollen source) and a wild soybean zone (recipient) (Fig. 1a). The size of pollen source was $72 \mathrm{~m} \times 3 \mathrm{~m}$ (7 rows). GM soybean cultivars with the different sowing dates described above, were arranged in a block design as shown by Figure 1a. The recipient wild soybeans were planted along 72 net walls. The 72 walls were mounted continuously at $2 \mathrm{~m}$ intervals between 2 and $10 \mathrm{~m}$ from pollen source in a staircase pattern. The walls arranged at $2,4,6,8,10 \mathrm{~m}$ distance from pollen source were used to estimate the effect of isolation by distance on natural hybridization between GM and wild soybean. Alternatively, one to four walls mounted in front of another wall (i.e. 0 wall in front of a $2 \mathrm{~m}$ wall; 1 wall in front of a $4 \mathrm{~m}$ wall; 0 or 2 walls in front of a $6 \mathrm{~m}$ wall; 1 or 3 walls in front of a $8 \mathrm{~m}$ wall; 0 or 2 or 4 walls in front of a $10 \mathrm{~m}$ wall) were treated as "buffer plant" when the effect of "buffer plant" on natural hybridization was calculated.

The mixed planting area (Fig. 1b) consisted of 29 plots of GM soybean (pollen source) and 28 walls of wild soybean (recipient). The distance between walls of wild soybean was $2.5 \mathrm{~m}$. In the interval, GM soybean cultivars with different sowing date were randomly arranged for each row in a plot and planted 4 rows $\times 10$ hills per a plot with $50 \mathrm{~cm}$ spacing between rows. Since the distance between GM and wild soybean was $0.5 \mathrm{~m}$, many vines of wild soybean had twined around GM soybean plants.

The monitoring area (Fig. 1c) was separated by $1 \mathrm{~m}$ from the other two areas to avoid human disturbance of pollen source area when GM soybean flowering were monitored. GM soybean cultivars with different sowing date was planted in three rows in a randomized block design with five replications.

\section{Monitoring of flowering phenology}

To assess flowering synchrony between GM and wild soybean, flowering phenologies of GM and wild soybean were monitored. The numbers of open flowers were counted within a day, at 2-3 days intervals during the flowering periods in both experimental years. The number of flowers on GM soybean was counted for five hills (in 2006) or four hills (in 2007) per a replication at five replications. The mean number of open flowers was calculated by using the pooled data from 25 (in 2006) or 20 (in 2007) hills for each experimental approach every monitoring day. The numbers of flowers on wild soybean were counted per a wall at eight monitoring walls in the spatial planting area (central walls at $6 \mathrm{~m}$ from a pollen source; see the arrows of Fig. 1). The mean number of flowers was calculated by using pooled data of the eight monitoring walls.

In some case, GM soybean cultivar and wild soybean flowered at the same time, the number of flowering overlap days were calculated. The date with the maximum number of flowers observed was defined as the date of flowering peak.

\section{Detection of hybridization}

\section{Harvest and screening for hybrid plants}

Fully matured seeds of wild soybeans were harvested from each wall in October 2006 and 2007. In 2006, 50587 seeds (about 1000 5000 seeds per a wall) were collected in the mixed planting area and 72000 seeds (1000 seeds per a wall) were collected in the spatial planting area. In 2007, 99086 seeds (about 1000 seeds per a wall) were collected in both areas. After the seeds were scarified, the seeds for each wall were separately sowed on trays filled with peat moss and maintained in a greenhouse. The numbers of emerging seedlings were counted 13-19 days after sowing. Glyphosate (1.66 kg a.i.ha ${ }^{-1}$ ) was sprayed on individual seedlings at the second to third leaf stage (2-3 weeks after sowing) following the method of Mizuguti et al. (2009). Surviving seedlings after glyphosate spray were considered hybrids with GM soybean.

\section{Immunochemical chromatographic test and SSR screeing}

An immunochemical chromatographic test (Trait RUR [Roundup Ready] Lateral Flow Test Kit; Strategic Diagnostics Inc., Newark, DE, USA) was used on $0.1 \mathrm{mg}$ leaf 
tissue from the suspected hybrid plant to confirm the expression of the CP4 EPSPS (glyphosate-tolerant) protein. The pollen parents of the hybrids were identified by using 20 SSR markers (Kuroda et al., 2006). Total DNA was extracted from young leaf tissue from each surviving plant. Each DNA sample was adjusted to approximately 5-20 ng. $\mu \mathrm{L}^{-1}$ and used as template DNA for PCR analysis. PCR amplification was carried out in a Thermal cycler (iCycler, BIORAD). The reaction mixture consisted of a total volume of $5 \mu \mathrm{L}$, containing $1.7 \mu \mathrm{L}$ of template DNA, $2.5 \mu \mathrm{L}$ of 2xQIAGEN Multiplex PCR Master Mix, $0.5 \mu \mathrm{L}$ of a primer pair $\left(5\right.$ pmol. $\left.\mu \mathrm{L}^{-1}\right)$, and $0.3 \mu \mathrm{L}$ of DNase free water. PCR amplification was perform in the thermal cycler programmed with initial activation step at $95^{\circ} \mathrm{C}$ for $15 \mathrm{~min}$ and 40 cycles each of $30 \mathrm{~s}$ at $94{ }^{\circ} \mathrm{C}$ for denaturation, $90 \mathrm{~s}$ at $57^{\circ} \mathrm{C}$ for annealing and $60 \mathrm{~s}$ at $72{ }^{\circ} \mathrm{C}$ for extension and $30 \mathrm{~min}$ at $60^{\circ} \mathrm{C}$ for final extension. After amplification, samples were kept at $4{ }^{\circ} \mathrm{C}$. One $\mu \mathrm{L}$ of the PCR product was denatured at $95{ }^{\circ} \mathrm{C}$ for $5 \mathrm{~min}$ after mixing with $10 \mu \mathrm{L}$ of Hi-Di formamide and $0.3 \mu \mathrm{L}$ of GeneScan-500LIZ size standard (Applied Biosystem). Denatured samples were analyzed using a 3100 Genetic analyser (ABI Prism) and the output data was analyzed using Gene Mapper 3.0 software.

\section{Statistical analysis}

Natural hybridization frequency was expressed as the number of detected hybrids divided by number of tested seedlings and recorded for each experimental approach (mixed planting, distance, number of barriers, GM soybean cultivars and experimental year). For comparison across experimental approaches, two-sided 95\% confidence intervals of the population proportions for the natural hybridization frequency at each distance class for both years and for each cultivar in 2007 were estimated using the relationship between the binomial distribution and $F$ distribution (Zar, 2010). This analysis was performed using the "binom.test" function from the base package in R v. 2.11.1 (R Development Core Team, 2010).

A generalized linear model was used to analyze the effects of temporal and spatial isolation on hybridization frequency. The numbers of detected hybrids and tested seedlings on each wall of wild soybean in 2007 were incorporated into the model. The data was fitted a quasipoisson model by computation of dispersion parameter, because the data exhibited under disparison relative to the Poisson distribution. The model was fitted using the "glm" function from the base package and the analysis of deviance for the model fits was performed using the "Anova" function from the CAR package in R v. 2.11.1 (R Development Core Team, 2010). The percentage of deviance explained by the factors tested was calculated (Faraway, 2006).

\section{ACKNOWLEDGEMENTS}

We thank the members of the Experimental Farm Management Division of the National Institute for AgroEnvironmental Sciences for assistance and encouragement. We also acknowledge Monsanto Company for provision of GM soybean seeds and valuable comments. This study was supported by a grant from the Ministry of Agriculture, Forestry and Fisheries of Japan (Assurance of Safe Use of Genetically Modified Organisms Project).

Received December 3rd, 2009; accepted August 19, 2010.

\section{REFERENCES}

Abud S, de Souza PIM, Vianna GR, Leonardecz E, Moreira CT, Faleiro FG, Júnior JN, Monteiro PMFO, Rech EL, Aragão FJL (2007) Gene flow from transgenic to nontransgenic soybean plants in the Cerrado region of Brazil. Genet. Mol. Res. 6: 445-452

Carlson JB, Lersten NR (2004) Reproductive morphology. In Soybeans, Improvement, Production, and Use, Boerma HR and Specht JE, eds, American Society of Agronomy/Crop Science Society of America/Soil Science Society of America, Madison, pp 59-95

D'Andrea L, Felber F, Guadagnuolo R (2008) Hybridization rates between lettuce (Lactuca sativa) and its wild relative (L. serriola) under field conditions. Environ. Biosafety Res. 7: 61-71

Della Porta G, Ederle D, Bucchini L, Prandi M, Verderio A, Pozzi C (2008) Maize pollen mediated gene flow in the Po valley (Italy): Source-recipient distance and effect of flowering time. Europ. J. Agronomy 28: 255-265

Ellstrand NC (2003) Current knowledge of gene flow in plants: implications for transgene flow. Phil. Trans. R. Soc. Lond. B 358: $1163-1170$

Faraway JJ (2006) 3.3 Negative binomial. In Extending the Linear Model with R: Generalized Linear, Mixed Effects and Nonparametric Regression Models, Chapman \& Hall/CRC, pp 63-66

Halsey ME, Remund KM, Davis CA, Qualls M, Eppard PJ, Berberich SA (2005) Isolation of maize from pollenmediated gene flow by time and distance. Crop Sci. 45: 21722185

Hancock JF (2003) A framework for assessing the risk of transgenic crops. BioScience 53: 512-519

Haygood R, Ives AR, Andow DA (2003) Consequences of recurrent gene flow from crops to wild relatives. Proc. $R$. Soc. Lond. B 270: 1879-1886

Hooftman DAP, Oostermeijer JGB, Marquard E, den Nijs H(J)CM (2008) Modelling the consequences of crop-wild relative gene flow: a sensitivity analysis of the effects of outcrossing rates and hybrid vigour breakdown in Lactuca. J. Appl. Ecol. 45: 1094-1103 
Hüsken A, Dietz-Pfeilstetter A (2007) Pollen-mediated intraspecific gene flow from herbicide resistant oilseed rape (Brassica napus L.). Transgenic Res. 16: 557-569

ISAAA (2009) Executive summary: Global Status of Commercialized Biotech/GM Crops: 2009. http://www. isaaa.org/

Karasawa K (1936) Crossing experiments with Glycine soja and G. ussuriensis. Jap. J. Bot. 8: 113-118

Kuroda Y, Kaga A, Tomooka N, Vaughan DA (2006) Population genetic structure of Japanese wild soybean (Glycine soja) based on microsatellite variation. Mol. Ecol. 15: 959-974

Kwon SH, Im KH, Kim JR (1972) [Studies on diversity of seed weight in the Korean soybean]. Korean J. Breed. 4: 7074 (in Korean with English abstract)

McPherson MA, Good AG, Topinka AKC, Yang RC, McKenzie RH, Cathcart RJ, Christianson JA, Strobeck C, Hall LM (2009) Pollen-mediated gene flow from transgenic safflower (Carthamus tinctorius L.) intended for plant molecular farming to conventional safflower. Environ. Biosafety Res. 8: 19-32

Messeguer J, Penas G, Ballester J, Bas M, Serra J, Salvia J, Palaudelmas M, Mele E (2006) Pollen-mediated gene flow in maize in real situations of coexistence. Plant Biotechnol. J. 4: $633-645$

Mizuguti A, Yoshimura Y, Ohigashi K, Kaga A, Kuroda Y, Matsuo K (2008a) Estimation of gene flow between wild and glyphosate-tolerant GM soybeans by honeybee in containment greenhouse. Symposium handbook of 10th ISBGMO, p 115

Mizuguti A, Yoshimura Y, Ohigashi K, Matsuo K (2008b) Comparison of the flowering phenology among the regional populations of wild soybean in Japan. Abstracts of 5th International Weed Science Congress, p 146

Mizuguti A, Yoshimura Y, Matsuo K (2009) Flowering phenologies and natural hybridization of genetically modified and wild soybeans under field conditions. Weed Biol. Manag. 9: 93-96

Morris W, Kareiva P, Raymer P (1994) Do barren zones and pollen traps reduce gene escape from transgenic crops? Ecol. Appl. 4: 157-165

Nakayama Y, Yamaguchi H (2002) Natural hybridization in wild soybean (Glycine max ssp. soja) by pollen flow from cultivated soybean (Glycine max ssp. max) in a designed population. Weed Biol. Manag. 2: 25-30

Ohigashi K, Mizuguti A, Yoshimura Y, Nakatani K, Araki H, Tuyuzaki H, Shimada H, Horimoto S, Nishiwaki A, Miwa T, Matsuo K (2009) A flowering model to estimate the potential of hybridization between wild and cultivated soybeans. J. Weed Sci. Tech. Suppl.: 118 (in Japanese with English title)
Oka H (1983) Genetic control of regenerating success in seminatural conditions observed among lines derived from a cultivated x wild soybean hybrid. J. Appl. Ecol. 20: 937-949

Palaudelmas M, Mele E, Penas G, Pla M, Nadal A, Serra J, Salvia J, Messeguer J (2008) Sowing and flowering delays can be an efficient strategy to improve coexistence of genetically modified and conventional maize. Crop Sci. 48: 2404 2413

R Development Core Team (2010) R: A language and environment for statistical computing. R Foundation for Statistical Computing, Vienna, Austria. http://www.R-project.org

Rognli OA, Nilsson NO, Nurminiemi M (2000) Effect of distance and pollen competition on gene flow in the windpollinated grass Festuca pratensis Huds. Heredity 85: 550560

Rong J, Lu B-R, Song Z, Su J, Snow AA, Zhang X, Sun S, Chen R, Wang F (2007) Dramatic reduction of crop-to-crop gene flow within a short distance from transgenic rice fields. New Phytol. 173: 346-353

Sameshima R (2000) Modeling soybean growth and development responses to environmental factors. Bull. Natl. Agric. Res. Cent. 32: 1-119 (in Japanese with English summary)

Song ZP, Lu B-R, Zhu YG, Chen JK (2003) Gene flow from cultivated rice to the wild species Oryza rufipogon under experimental field conditions. New Phytol. 157: 657-665

Staniland BK, McVetty PBE, Friesen LF, Yarrow S, Freyssinet G, Freyssinet M (2000) Effectiveness of border areas in confining the spread of transgenic Brassica napus pollen. Can. J. Plant Sci. 80: 521-526

Tateishi Y, Ohashi H (2001) Subtribe V. Glycininae 62. Glycine Willd. In Flora of Japan, Vol. IIb Angiospermae Dicotyledoneae Archilamydeae (b), Iwatsuki K, Boufford DE and Ohba H, eds, Kodansha, Tokyo, pp 276-277

Thompson CJ, Thompson BJP, Ades PK, Cousens R, Garnier-Gere P, Landman K, Newbigin E, Burgman MA (2003) Model-based analysis of the likelihood of gene introgression from genetically modified crops into wild relatives. Ecol. Model. 162: 199-209

Wolf DE, Takebayashi N, Rieseberg LH (2001) Predicting the risk of extinction through hybridization. Conserv. Biol. 15: 1039-1053

Xu DH, Abe J, Gai Y, Shimamoto Y (2002) Diversity of chloroplast DNA SSRs in wild and cultivated soybeans: evidence for multiple origins of cultivated soybean. Theor. Appl. Genet. 105: 645-653

Yoshimura Y, Matsuo K, Yasuda K (2006) Gene flow from GM glyphosate-tolerant to conventional soybeans under field conditions in Japan. Environ. Biosafety Res. 5: 169-173

Zar JH (2010) 24.8 Confidence limits for a population proportion. In Biostatistical Analysis Fifth Edition, Pearson Education, Inc., Upper Saddle River, New Jersey, USA, pp 543-548 